\title{
Eigenvalue Buckling Computation and Impact on Pipeline Wall Thickness and Subsea Depth
}

\author{
Enefola S. Ameh ${ }^{1}$, Bamisedun A. Adekunle ${ }^{2}$, C.V.Ossia ${ }^{3}$ \\ ${ }^{1}$ (Mechanical Department, University of Benin, Nigeria) \\ ${ }_{3}^{2}$ (Offshore Technology Institute, University of Port Harcourt, Nigeria) \\ ${ }_{3}^{3}$ (Offshore Technology Institute, University of Port Harcourt, Nigeria)
}

\begin{abstract}
Submarine pipelines used in the transportation of hydrocarbon in the oil and gas industry are usually subjected to external hydrostatic pressure and compressive stresses resulting in susceptibility to buckling and loss of structural stability. The objective of the present work was to examine influence of wall thickness on eigenvalue buckling load and hydrostatic pressure on ocean depth. Linear buckling analysis was conducted employing finite element method using ANSYS software package and the simulation was conducted varying wall thickness and ocean depth. The investigation showed collapse buckling pressure decreased linearly with ocean water depth but increased with thickness increment. Pipeline buckling failure can be minimized with wall thickness optimization design and selection.
\end{abstract}

Keywords: Buckling, external hydrostatic pressure, pipelines, wall thickness

\section{Introduction}

Pipelines are critical facility in the petroleum industry and are used in long distance transportation of hydrocarbon products such as inflammable gases, liquid and crude oil. It remains the safest and cost effective means of transporting hydrocarbon from reservoir wells to production and storage facility [1]. Several submarine pipelines are being operated under high internal temperature and external pressure that consequently lead to resultant compressive stresses which make the pipelines susceptible to buckling. Pipeline buckling occurs due to frequently cyclic expansion and contraction in axial direction because of internal heating and cooling due to process start-up and shut-down and the restriction movement at anchor points [2]. Secondly, pipeline structure that are laid in ocean usually experience water pressure with increasing depth. This pressure is considered external and different from pressure present in the structure. Pipelines are often laid empty during installation thus residual atmospheric pressure is left-in. The difference in the external and internal pressure induced resultant stress in the pipeline [3]. Buckled pipeline structure leads to loss in stiffness matrix and loadcarrying capacity stability that cause damaging effect on pipeline integrity [4]. Theoretical buckling pressure for thin wall cylindrical shell under the action of axial lateral pressure with supports at both ends was presented [5] as:

$$
P_{C y}=\frac{E(t / a)}{\left[n^{2}-1+0.5(\pi a / n) 2\right]} \times\left\{\frac{1}{\left[n^{2}\left([/ \pi a)^{2}+1\right]\right.}+\frac{t^{2}}{\left[12 a^{2}\left(1-v^{2}\right)\right]}\left[n^{2}-1+(\pi a / l)^{2}\right]^{2}\right\}
$$

where, $P_{c y}=$ buckling pressure, $t=$ wall thickness, $a=$ radius of cylindrical shell, $l=$ unsupported cylindrical length, $E=$ Young Modulus, $v=$ Poisson ratio and $n=$ number of circumferential lobes. But in eigenvalue analysis, load modelled with stiffness matrix was assumed to be become singular so that the problem has nontrivial solutions [6] expressed as:

$\{P\}=\{K\}\{\mathrm{U}\}$

where, $P=$ applied force and $\mathrm{U}=$ displacement. But the compressive applied load on the structure develops initial stress matrix given as:

$\{\Delta P\}=\left[\left\{K_{\theta}\right\}+\lambda\left[K_{\sigma}\left(\sigma_{0}\right)\right]\right]\{\Delta \mathrm{U}\}$

where, $\left\{K_{\varepsilon}\right\}=$ elastic stiffness matrix, $\left[K_{\sigma}\left(\sigma_{0}\right)\right]=$ initial stress matrix, $\Delta \mathrm{U}=$ displacement associated with buckling shape and $\lambda=$ buckling load factor.

\section{Literature Survey}

Critical buckling load which correspond to starting failure point of structure is often computed using eigenvalue analysis by assuming pre-buckling displacement [7]. Eigenvalue mode of analysis was showed as the quickest method to evaluate critical buckling load of structure combined with marginal safety factor [8]. Investigation of compression force reduction and enhanced trawl pull over resistance by installing pipeline in controlled buckled shape conducted indicated geometry and configuration contributed to pipeline residual stress and out-of-straightness [9]. Examination of pipelines buckling propagation under external pressure and dynamic 
conditions using analytical method was studied. The analytical results were further validated with experimental and finite element methods and all the results were found to be in agreement [10]. Linear and nonlinear buckling of a steel bar using numerical techniques and Abacus software package had been studied [8]. The linear buckling analysis showed agreement with existing theory. However, the analysis of post buckling non-linear behavior was unstable with small incremental load values. In elastic buckling of tube under external hydrostatic pressure with imperfection was studied using finite method. The finite element used was 8 nodes shell93 and translated in $\mathrm{x}, \mathrm{y}$ and $\mathrm{z}$ nodal directions and rotation on the same plane with six degree of freedom at each node [11]. Experiment on aluminum specimen was performed and compared to ANSYS model. The specimens were subjected to axial compression between two rigid plates and the load-deflection relationship showed linearity. The experimental result was found to be analogous to the numerical result and concluded finite element method was a more cost and time effective way to determining buckling load [12].

Corroded pipelines region with non-uniform thickness subjected to buckling pressure propagation showed the non-uniformly corroded pipeline failed by local or shell buckling pressure [13] while the subsea pipeline subjected to buckling pressure following hyperbaric chamber and ring squash experiments and validated with modified analytical and finite element methods all showed significant incremental eigenvalue buckling load [14]. Susceptibility of cylindrical submarine hull buckling for interstiffener and buckling configuration with a view to optimizing design was investigated. The finding indicated significant increase and high resultant compressive stress due to high hydrostatic pressure but introduction of stiffener was found to reduce the resultant compressive stress leading to improved buckling strength [15]. Investigation of thin-walled buckling shell with ANSYS finite element software package showed unusually high buckling loads and stress increment with wall thickness variation [16]. Fixed offshore jacket tube subjected to linear and non-linear buckling under internal and external pressure was studied and the jacket tube was found excessively deformed locally and buckled with small incremental load. But the buckling initiation pressure was reported to decrease rapidly with increasing ratio of wall thickness to tube diameter [17]. Several literatures reviewed had shown to have considered effect of internal and external pressure but rarely has pipeline wall thickness relative to external hydrostatic pressure investigated. Significant of design codes do not take external hydrostatic pressure into cognizance in design against buckling propagation for pipelines exposed to deep water particularly in West African and Gulf of Mexico oceans. The aim of the present study was to investigate the impact of external hydrostatic pressure on pipeline wall thickness selection and subsea depth. The relevance of the study includes optimizing pipeline wall thickness selection and design enhancement to avoid preventable buckling and maintain mechanical integrity of submarine pipeline through its life span.

\subsection{Pipeline Material and Properties}

\section{Materials and Methodology}

The pipeline material used in the study is American Petroleum Institute (API) 5L X42 carbon steel with different wall thickness as shown in Table1. Mechanical Properties of the X42 grade steel are given in Table 2.

Table 1: X42 steel grade varying wall thickness

\begin{tabular}{|l|l|l|}
\hline Pipe Schedule & Pipe diameter(mm) & Wall thickness $(\mathbf{m m})$ \\
\hline 30 & 457.2 & 11.13 \\
\hline XS & 457.2 & 12.70 \\
\hline 40 & 457.2 & 14.27 \\
\hline 60 & 457.2 & 19.15 \\
\hline 80 & 457.2 & 23.36 \\
\hline 100 & 457.2 & 29.36 \\
\hline 120 & 457.2 & 34.93 \\
\hline 140 & 457.2 & 39.67 \\
\hline
\end{tabular}

Table 2: Mechanical Properties of X42 steel grade

\begin{tabular}{|l|l|l|}
\hline Properties & Unit & Value \\
\hline Tensile strength & $\mathrm{MPa}$ & 415 \\
\hline Yield Strength & $\mathrm{MPa}$ & 290 \\
\hline Steel Density & $\mathrm{Kg} / \mathrm{m} 3$ & 7850 \\
\hline Modulus of Elasticity & $\mathrm{MPa}$ & $2.00 \mathrm{E}+4$ \\
\hline Poisson Ratio & - & 0.295 \\
\hline
\end{tabular}

\subsection{Finite Element Method}

Finite element analysis methodology was employed in the present study using ANSYS software package in the sequence of pipe geometry modelling, followed by material properties data input, meshing, boundary condition application, application of load and running of analysis to extract Von Mises stresses and post processing of eigenvalue buckling pressure solutions. 
Pipe geometry: Pipeline was modelled as $200 \mathrm{~m}$ of length and $457.2 \mathrm{~mm}$ outer diameter size. The thickness of the pipe was varied from schedule 30 to 140 at a constant water depth of $1000 \mathrm{~m}$ and the Eigenvalue collapse pressure computed. While second analysis scenario considered water depth variation from $400 \mathrm{~m}$ at a step of $200 \mathrm{~m}$ at constant thickness of XS schedule.

Meshing: The section of the pipeline considered was meshed to discretize the pipe body to elements. Configuration of the mesh was set at $2 \mathrm{~m}$ element size which produced 1500 elements and 8000 nodes. Pipe cross sectional face was meshed separately to avoid convergence problem. Type of element utilized in the buckling analysis was Plane 82 which is 2-dimensional and 8 nodal elements that have triangular and quadrilateral mesh.

Boundary condition: The model assumed a pipeline connection to wellhead and manifold, implying both ends of the pipeline was constrained so that $u x=u y=u z=0$ which means that all rotational and translational degree of freedoms are constrained. The pipeline was exposed on a seabed experiencing hydrostatic pressure and the seabed was modelled as flat, plane and rigid surface.

Application of Load: Loads acting on the pipeline were modelled as internal and external pressure. The applied external hydrostatic pressure was facing downward prior to laying the pipeline on the seabed, followed by filling with crude oil density of $870 \mathrm{~kg} / \mathrm{m}^{3}$, internal operating pressure and temperature set at $5^{\circ} \mathrm{C}$.

\section{Result and Discussion}

Distinctive buckling mode shapes for schedule XS presented in Fig 1 and 2 do not change with varying water depth for the different simulated modes, however, the maximum deformations were observed to increase relative to the buckling modes. The significant change in buckling modes shapes between mode 1, 2, 3 and 4 loads for each water depth was an indication that when pipe buckled in mode 1 load, it becomes unstable and only requires lesser amount of load to cause further deformation in subsequent loading. The observation was in agreement with the reported work [17] that amount of pressure needed to cause further buckling propagation decreased rapidly with thickness increment in subsequent loading. However, the buckling mode shapes for schedule 30, 40 and XS (Fig 3 - 5) showed significant buckling mode shape changes with wall thickness variation at a constant water depth and reduction in maximum deformation with incremental thickness. Plot of critical eigenvalue buckling values versus pipeline wall thickness (Fig 6) indicated critical buckling load increased with wall thickness increment. Thus, substantial thickness increment improves pipeline strength and resistance to buckling. The finding was in agreement with the report that buckling load increased linearly with wall thickness variation of hull structure [16].

External hydrostatic pressure versus pipeline water depth (Fig 7) showed hydrostatic pressure increased linearly with water depth. This implied that as offshore pipeline move deeper into the ocean, the pressure of water on pipeline increase leading to external hydrostatic pressure increment and consequently increased the rate of pipeline susceptibly to bucking and loss of stability and reduction of critical buckling load. The incremental external pressure could be attributed to building of water weight above the pipeline which consequently increase hoop stresses and become too extreme relative to wall thickness. Fig 8 presented a graph of compressive stress versus wall thickness change at a constant $1000 \mathrm{~m}$ water depth. The compressive stresses were observed to decrease with increasing wall thickness change which implied thicker pipeline experiences lesser resultant stress. The equivalent stresses were computed as Von Mises stresses that measure resultant principle stresses. Thus, increase stress without corresponding incremental wall thickness increased susceptibility of pipeline to buckling. However, pipeline with residual stress inherited during manufacturing process may attain their critical stresses lower than predicted which may affect critical buckling load.

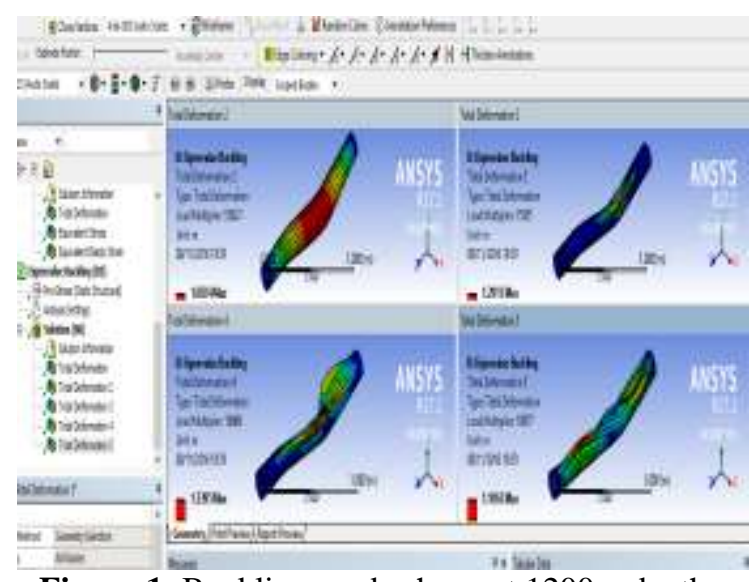

Figure 1: Buckling mode shape at $1200 \mathrm{~m}$ depth

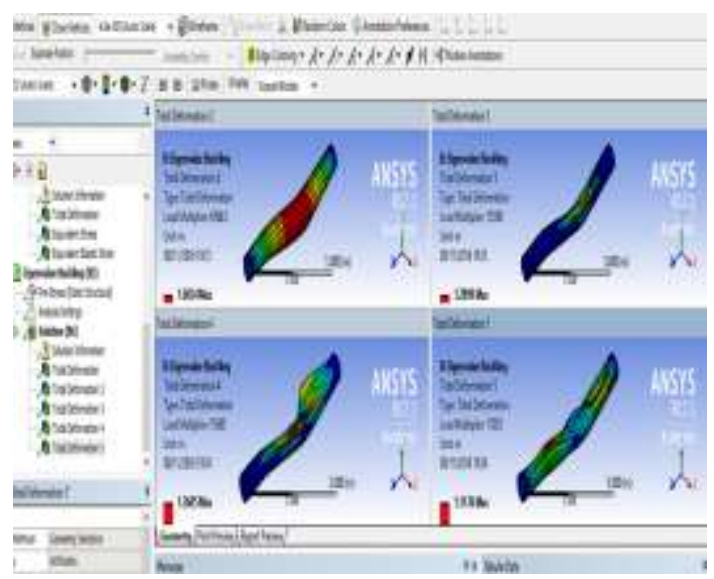

Figure 2: Buckling mode shape at $1400 \mathrm{~m}$ depth 


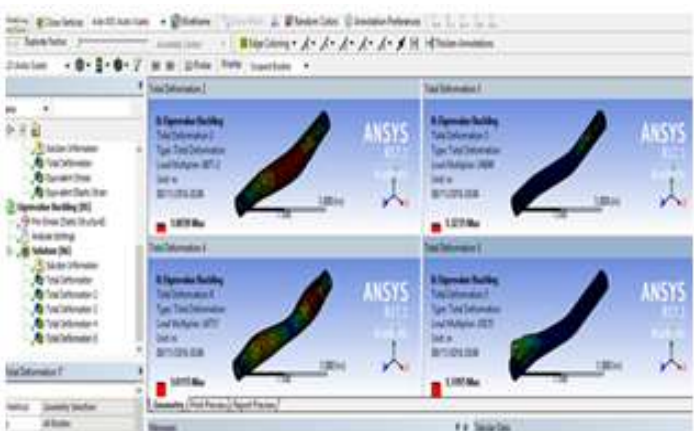

Figure 3: Buckling mode shape for Schedule 30

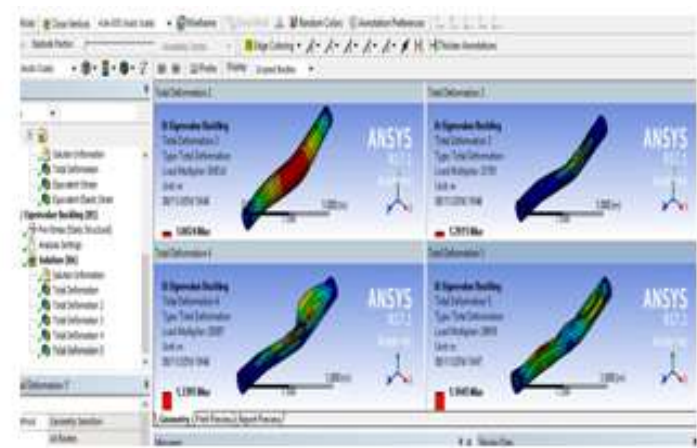

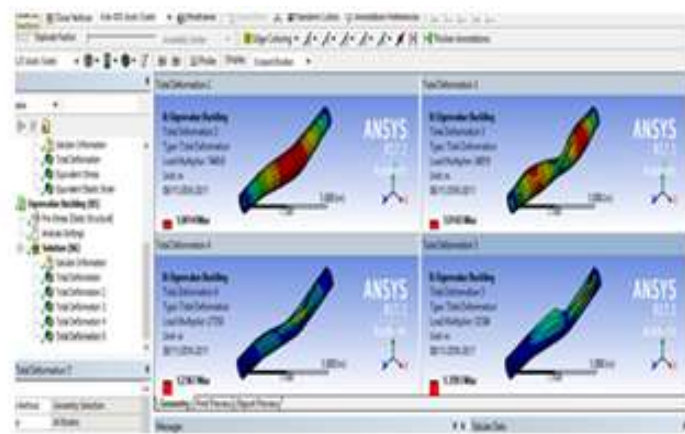

Figure 4: Buckling mode shape for Schedule 40

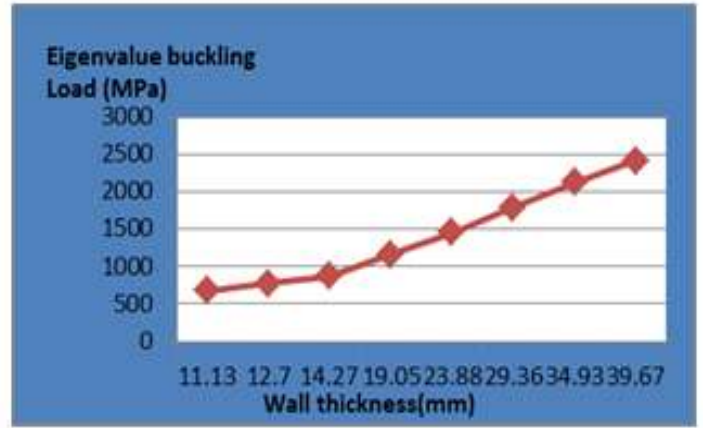

Figure 5: Buckling mode shape for Schedule XS Figure 6: Eigenvalue buckling load versus wall thickness

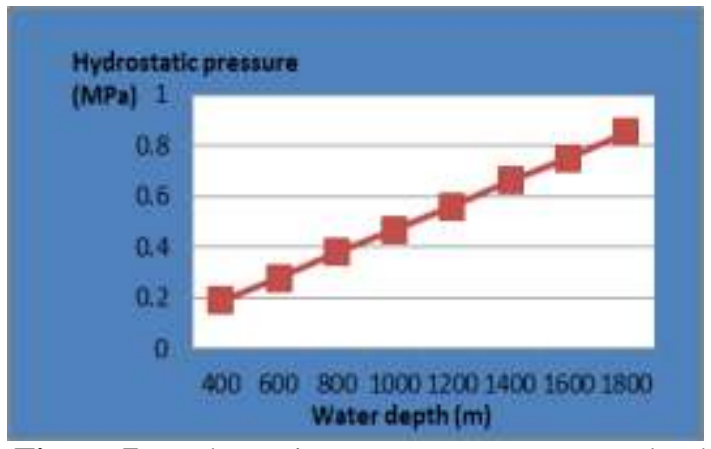

Figure 7: Hydrostatic pressure versus ocean depth

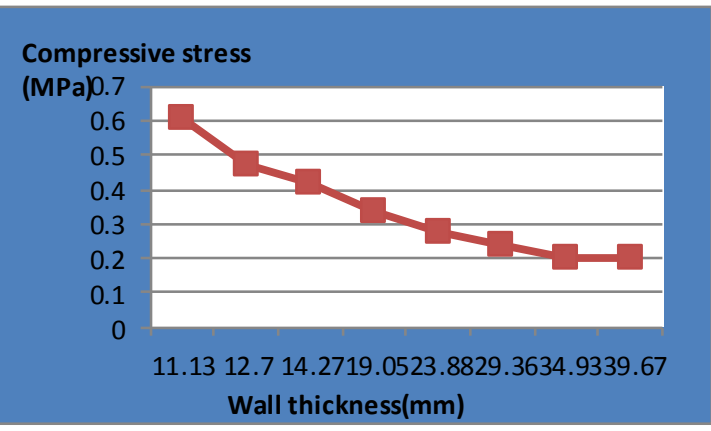

Figure 8: Buckling compressive stress versus wall thickness

\section{Conclusion}

Finite element method employed in the computation of eigenvalue buckling load and analysis proved to be satisfactory and helped to optimize design against buckling. The computed eigenvalue critical buckling load and compressive stresses showed linear variation with wall thickness, therefore, buckling failure could be minimized with optimal wall thickness selection. But subsea pipelines buckled due to external hydrostatic pressure resulting from water depth and water weight above the pipeline. The external hydrostatic pressure was found to increase with ocean depth and significant on submarine pipelines, therefore, impact of external pressure is necessary to be considered in pipeline wall thickness design.

\section{References}

[1]. M. Mohitpour, H. Goshan, and A. Murray, Pipeline design and construction- A Practical Approach, (ASME Press, New York, 2000)

[2]. M. D. Carr, D.A.S. Bruton and D. Leslie, Lateral Buckling and Pipeline Walking, A Challenge For Hot Pipeline, Offshore Pipeline Technology Conference, Amsterdam, 2003.

[3]. J. T. McDaniel, J. T. McDaniel official website, 2011, [Accessed $15^{\text {th }}$ December, 2016].

[4]. A. M. Reda and G. L. Forbes, Investigation into The Dynamic Effects of Lateral Buckling of High Temperature/High Pressure Offshore Pipeline, Review of Acoustic Proceeding, Paper number 83, 2012, Australian Acoustical Society.

[5]. Von Mises, Der Kritische Aussendruck Fur Allseits Belastete Zylindrische Rohre, Report No.366, 1936, Washington D.C.USA.

[6]. M. Zyczkorosky, 'Post-Buckling Analysis of Non-Prismatic Columns under General Behaviour of Loading, International Journal of Non-linear Mechanics, Vol3, 2005, 45-56.

[7]. V. D. Silva, Mechanic and strength of materials, Springer, 2006, Netherlands. 
[8]. S. Novoselac, T. Ergic, and P. Balicevic, Linear and Non-linear Buckling and Post -Buckling Analysis of a Bar with the Influence of Imperfection, Technical Gazette 19, 2012, 695-701.

[9]. P. S. Frederiksen, J. B. Andersen and H. J. Porty, Controlled Lateral Buckling of Submarine Pipelines in Snaked Configuration, 17 International Conference on Offshore Mechanics and Artic Engineering, Lisbon, Portugal, 1998.

[10]. S. Kyriakides and T. A. Netto, Dynamics of Propagation Buckles in Pipelines, International Journal of Solids and Structure, Vol 37, 2000, 6843-6867.

[11]. P. F. Andrew, L. C. T. F. Ross and D. Graham, Inelastic Buckling of Geometrically Imperfect Tubes under External Hydrostatics Pressure, Peer Review, 2008.

[12]. N. K. Gupta, N. M. Sheriff and R. Velmurugan, Buckling of Thin Conical Frustrum under Axial Load, International Journal of Engineering Science And Technology, 2006, 86-96.

[13]. J. Xue and M. S. H. Fatt, Buckle Propagation of in Pipeline with Non-Uniform thickness, Ocean Engineering, Vol 28, 2001, 13831389.

[14]. F. Alberani, H. Khalilpasa and Karampor, Propagation Buckling in Deep Subsea Pipeline, Engineering Structure, $2011,2547-2553$.

[15]. P. R. Sreelatha and A. Mathai, Linear and Non-Linear Buckling Analysis of Stiffened Cylindrical Submarine Hull, International Journal of Engineering Science and Technology, Vol 4, 2012, 0975-5462.

[16]. T. Subramani and A. Sugathan, Finite Element Analysis of Thin Walled Shell Structures by ANSYS and LS-DYNA, International Journal of Modern Engineering Research, Vol 2, 2012, 1576-1587.

[17]. A. Elshafey, M. R. Haddara, H Marzouk and M. El-shami, Non- Linear Buckling of Pipes Subjected to External or Internal Pressure, International Journal of Recent Trends in Engineering and Technology, Vol 3, 2010. 